\title{
Erratum to: Endocannabinoids underlie reconsolidation of hedonic memories in Wistar rats
}

\author{
Cristiane Ribeiro De Carvalho • \\ Fabrício Alano Pamplona • Jéssica Silveira Cruz • \\ Reinaldo Naoto Takahashi
}

Published online: 7 December 2013

(C) Springer-Verlag Berlin Heidelberg 2013

Erratum to: Psychopharmacology (Berl) 2013 Nov 19. [Epub ahead of print]

DOI 10.1007/s00213-013-3331-2

There was an inadvertent error in Figure 1 of the online version of this article. The data that originally appeared in this figure was exactly the same data plotted in Figure 2 (painel A-C). The Figure 2 is correct and the published Figure 1 (painel A-C) should be replaced with the following original figure. The published legend for Figure 1 is not affected in any way and is reproduced here in its entirety. The corresponding author regrets the error that occurred during editing process of figures and accepts sole responsibility for this mistake. This error does not change the scientific conclusions of the article in any way. The authors apologize for this error.

The online version of the original article can be found at http://dx.doi.org/ 10.1007/s00213-013-3331-2.

C. R. De Carvalho $(\bowtie) \cdot$ J. S. Cruz $\cdot$ R. N. Takahashi Laboratory of Psychopharmacology, Department of Pharmacology,

Universidade Federal de Santa Catarina, Campus Universitário

Trindade, 88049-900 Florianópolis, SC, Brazil

e-mail: decarvalhocr@gmail.com

F. A. Pamplona

D’Or Institute for Research and Education, Rio de Janeiro, Brazil

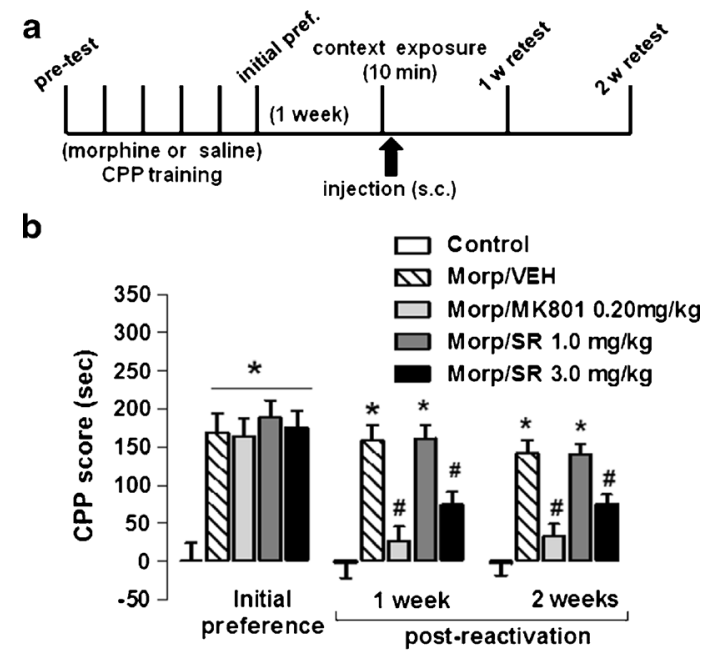

C

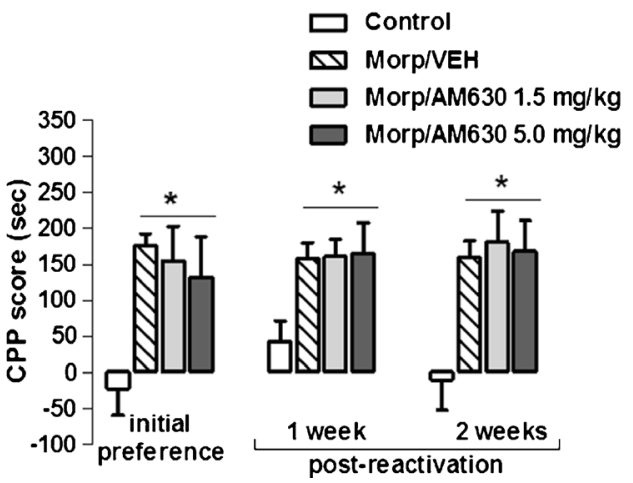

Fig. 1 Role of CB1 and CB2 cannabinoid receptors on the reconsolidation of morphine induced CPP. a Schematic protocol diagram. b Rats previously treated with morphine during CPP training were exposed to the context and immediately after receiving the $\mathrm{CB} 1$ cannabinoid receptor antagonist SR141716A $(0.0,1.0$, or $3.0 \mathrm{mg} / \mathrm{kg})$ or the NMDA antagonist MK-801 $(0.2 \mathrm{mg} / \mathrm{kg})$ as positive control. c Similar to "B," except that morphinetrained rats received the CB2 cannabinoid receptor antagonist AM630 (0.0, 1.5 , or $5.0 \mathrm{mg} / \mathrm{kg}$ ). CPP score (means $+\mathrm{SEM}$ ) is the difference between the time spent in the drug-paired compartment on the post-conditioning test and the pretest baseline (in seconds). ${ }^{*} p<0.05$ vs. control group; \#p $<0.05$ vs.Morp/ /VEH group ( $\mathrm{N}=9-11$ /group 